\title{
Objective and subjective memory impairment in elderly adults: a revised version of the Everyday Memory Questionnaire
}

\author{
Marco Calabria1, Rosa Manenti², Sandra Rosini², Orazio Zanetti ${ }^{2}$, Carlo Miniussi ${ }^{2,3}$ and Maria Cotelli² \\ 1Department of Technology, Universitat Pompeu Fabra, Barcelona, Spain, 2IRCCS Centro San Giovanni di \\ Dio Fatebenefratelli, Brescia, Italy, 3Department of Biomedical Sciences and Biotechnologies and National \\ Institute of Neuroscience, University of Brescia, Brescia, Italy
}

\begin{abstract}
Background and aims: Growing interest in understanding the relationship between subjective memory complaints (SMCs) and objective measures of memory abilities emphasizes the importance of SMC assessment for diagnostic purposes. The present study investigated the relationship between SMCs and objective memory deficits in elderly adults by analysis of the factor structure of the Everyday Memory Questionnaire (EMQ). Methods: Objective and subjective assessment of memory function was carried out in 112 elderly adults. Principal component analysis was then performed to study the factor structure of the EMQ in relation to the assessment. Results: Objective memory impairment was evident in $8.9 \%$ of elderly adults. The factor analysis showed that the most interpretable solution to detect objective changes with the EMQ comprised only 20 out of 28 items of the original list, with three factors explaining $48 \%$ of total variance. This version was more sensitive for detecting SMCs in elderly adults, since one out of the three factors was able to differentiate subjects with objective memory deficits from those without. Conclusion: Taken together, these results illustrate that this 20-item version of the revised EMQ may serve as an easy-to-use instrument during clinical screening, to evaluate objective memory impairment in individuals who report SMC.
\end{abstract}

(Aging Clin Exp Res 2011; 23: 67-73)

๑2011, Editrice Kurtis

\section{INTRODUCTION}

Aging-related cognitive changes are characterized by a long-term memory decline, mainly of the ability to encode and retrieve events from everyday life (i.e., episodic memory) $(1,2)$. As well as this objective memory decline, subjective memory complaints (SMCs) are commonly reported by elderly adults, with a prevalence estimated from $11 \%$ (3) to $60 \%$ (4).

Several studies have investigated the relationship between objective and subjective memory deficits, suggesting the predictive role of SMCs for cognitive decline $(3,5$ 7). Geerlings et al. (3) found that SMCs were associated with later development of Alzheimer's disease in subjects with normal objective cognition at baseline. Along the same lines, Glodzik-Sobanska et al. (5) conducted a longitudinal study with a eight-year follow-up in healthy elderly individuals, showing that the presence of SMCs contributes to the risk of future decline.

Other studies have reported no such predictive feature of SMCs for cognitive decline $(4,8)$ and some have shown that SMCs are mainly related to personality traits (7) or depressive symptoms (9), more than to objective memory loss.

The inconsistent results reported so far in the literature raise the question about how SMCs are rated. Therefore, a critical point about SMC assessment is methodology: how questionnaires are structured and their sensibility and sensitivity. In general, SMCs are rated through a series of simple questions or a structured or semi-structured questionnaire. Thus, sensitivity in detecting the complaints changes from one study to another (for methodological issues, see [10]).

The Everyday Memory Questionnaire (EMQ) was proposed by Sunderland et al. to rate SMCs (11). In its original version, the EMQ comprised 35 items describing memory failures of everyday life; it was later modified to a 28-item version (12). The factor structure of the EMQ has been studied in closed head injury patients (12), elderly adults (13) and multiple sclerosis patients (14). Sunderland et al. (13) applied the EMQ to a group of elderly adults

Key words: Aging, Everyday Memory Questionnaire, memory deficits, subjective memory complaints.

Correspondence: Maria Cotelli, PhD, IRCCS Centro San Giovanni di Dio Fatebenefratelli, Via Pilastroni 4, 25125 Brescia, Italy.

E-mail: mcotelli@fatebenefratelli.it

Received November 20, 2009; accepted in revised form February 18, 2010. 
and found that it had low test-retest reliability, although other authors studying the same factor structure reported its usefulness $(15,16)$. In particular, Cornish (15) examined the EMQ factor structure in a large population of undergraduate students, and proposed a five-factor structure, suggesting that a 28 -item version of the EMQ might provide a means of studying memory phenomena.

Recent growing interest in studying the relation of SMCs with objective memory measures is emphasized by the fact that SMCs may be a crucial clinical feature of diagnostic criteria in patients with amnesic Mild Cognitive Impairment (17-19), one of the clinical population with higher risk of development of dementia. Evaluation of the usefulness of SMCs in predicting the onset of memory deficits in the elderly population is an important field of research, due to its clinical importance (for a review, see [20]). Indeed, all knowledge about the relation of SMCs and objective memory measures has an influence in clinical practice for the diagnosis of cognitive decline $(21,22)$ and for prognosis to development of dementia (6).

In the present study, we analysed responses to the EMQ with the aim of investigating the relationship between SMCs and objective memory impairment in elderly adults. We also aimed at determining an improved factor structure for the EMQ in the elderly population and evaluating its psychometric properties. To date, only one study has used the EMQ in the elderly (13) and failed to demonstrate its reliability in this population. Evaluation of the EMQ factor structure in the elderly may help to define its sensitivity and reliability and therefore its usefulness in the clinical setting.

\section{METHODS}

\section{Participants and Cognitive Evaluation}

A total of 112 elderly adults were recruited via a newspaper advertisement to take part in a weekly four-session course about age-related changes in memory at the IRCCS Centro San Giovanni di Dio Fatebenefratelli of Brescia, Italy.

The demographic and cognitive data of participants are listed in Table 1.

Table 1 - Demographic characteristics and cognitive test scores of elderly participants $(n=112)$.

\begin{tabular}{lcc}
\hline & $\begin{array}{c}\text { Elderly Participants } \\
(\mathbf{n = 1 1 2})\end{array}$ & Cut-off \\
\hline Gender (male/female) & $25 / 87$ & \\
Age (yrs) & $70.8(6.2)$ & \\
Education (yrs) & $10.1(4.2)$ & \\
MMSE & $28.3(1.5)$ & $>24$ \\
Story Recall & $11.6(4.7)$ & $>7.5$ \\
Trail Making A & $51.4(25.5)$ & $<93$ \\
Trail Making B & $149.2(81.4)$ & $<282$ \\
\hline
\end{tabular}

All participants underwent a semi-structured interview recording their medical and psychiatric history, as well as present medical condition and medication usage. In addition, a cognitive assessment aimed at identifying participants with memory impairment. The brief cognitive assessment included a screening test for dementia (MMSE) (23), a verbal long-term memory evaluation (Story Recall) (24) and an executive functions test (Trial Making Test) (25). The assessment was administered and scored according to published procedures $(26,27)$.

The EMQ was administered a week after the cognitive assessment by an experimenter blind to the experimental purpose of the study. The 28-item version of the EMQ was used for the evaluation of memory complaints (12, $13,15)$. Each item is rated on a 9-point scale according to the frequency with which subjects experienced a specific event over the past six months. The higher the score, the higher the frequency of the experience of that item (1: not at all in the last six months; 2 : once in the last six months; 3: more than once in the last six months, but fewer than once a month; 4: once a month; 5: more than once a month, but fewer than once a week; 6: once a week; 7: more than once a week, but fewer than once a day; 8: once a day; and 9: more than once a day). A detailed explanation of the response scale was provided by the experimenter and then each participant self-rated each item of the EMQ (see Appendixes 1 and 2 for complete list of items).

Exactly the same assessment was repeated one year after the initial assessment, in a subset of 35 participants without memory deficits, in order to evaluate reliability over time.

\section{RESULTS}

Neuropsychological tests and the EMQ

For the Story Recall task, 10 out of 112 participants (8.9\%) scored below the normal range (2 standard deviations below the normal range, compared with an age- and education-matched population). The cognitive assessment results were used to identify Low Performers (LP) as participants with objective memory impairment, and Normal Memory participants (NM) as those without objective memory difficulties. T-tests for independent samples were employed to check for differences between groups (LP vs NM). LPs were significantly $(p=0.05)$ older $(74.4 \pm 5.1)$ than NMs $(70.4 \pm 6.2)$. They also had lower MMSE scores compared with NMs (LP: $27.0 \pm 1.4$; NM: $28.5 \pm 1.4$; $p=0.01)$. The two groups did not differ significantly with regard to the Trial Making Test (TMT) A $(p=0.690)$ and B $(p=0.185)$. Table 2 gives more details.

LPs did not show a significantly different score in the 28item EMQ when compared with NMs (LP: $71.7 \pm 21.0$; NM: $60.3 \pm 19.1 ; p=0.130)$. Therefore, no differences on the 28-item EMQ scores were found with respect to the objective memory differences revealed between the two groups. 
Table 2 - Demographic characteristics and cognitive test scores of elderly participants as a function of presence $(n=10)$ or absence $(n=102)$ of an objective memory deficit.

\begin{tabular}{lcccc}
\hline & $\begin{array}{c}\text { Normal Memory } \\
\text { Participants (n=102) }\end{array}$ & $\begin{array}{c}\text { Low performers } \\
\text { (n=10) }\end{array}$ & Cut-off & $p$-value \\
\hline Gender (male/female) & $24 / 78$ & $1 / 9$ & & \\
Age (yrs) & $70.4(6.2)$ & $74.4(5.1)$ & & 0.05 \\
Education (yrs) & $10.1(4.3)$ & $9.5(3.4)$ & $>24$ & 0.65 \\
MMSE & $28.5(1.4)$ & $27.0(1.4)$ & $>7.5$ & $<0.01$ \\
Story Recall & $12.3(4.2)$ & $4.4(2.8)$ & $<93$ & $<0.01$ \\
Trail Making A & $51.1(20.4)$ & $54.8(18.5)$ & $<282$ & 0.69 \\
Trail Making B & $144.6(76.8)$ & $196.3(111.7)$ & & 0.18 \\
\hline
\end{tabular}

\section{Factor structure}

With the 1986 version of Sunderland et al. (28 items) of the EMQ, no significant differences were found on the EMQ between participants scoring within the normal range and those scoring below it. From this first result, we moved to a deeper analysis to identify an alternative factor structure of the EMQ, more sensitive to detect SMCs in participants with objective memory deficits. For this purpose, we performed principal component analysis to study the EMQ factor structure in the normal NM group $(n=102)$, in order to find the best structure to be used in elderly people.

We first performed principal component analysis with oblimin rotation. Reliability was verified with Cronbach's alpha, which showed good consistency (0.86) within the questionnaire as a whole. A solution of nine factors was found, explaining $70.8 \%$ of total variance.

We then eliminated items which obtained lower means or which did not load onto components. Eight items were excluded $(2,4,11,19,20,23,26,27)$ to reach a finer factor structure. A second analysis with the remaining items was run and revealed a solution of seven components, explaining $68.9 \%$ of total variance. Principal component analysis with an oblimin rotation was then performed on the responses on the remaining 20 items. Oblique rotation was adopted, because no a priori hypothesis was made, by means of the 'scree test' method (28). Inspection of the eigen values suggested that a four- or three-factor solution was optimal. According to previous works on EMQ and factor structure (15), fourand five-factor solutions are the most frequently reported structure for this questionnaire. Accordingly, a four-factor solution that indicated non-coherent structure was first tested, with several items loading on different components. This solution accounted for $55 \%$ of total variance. A three-factor solution was also run and, in this case, a more easily interpretable structure was defined. Nine of these 20 items loaded onto a first component, and their loadings ranged from 0.92 to 0.47 . Another six items loaded onto a second component, loadings being from 0.75 to 0.42 . The remaining five items loaded onto a third com- ponent, ranging from 0.84 to 0.62 . In all, the four factors accounted for $48 \%$ of total variance. Reliability was checked with Cronbach's alpha, and good consistency (0.83) was found within this new set of items.

According to the items considered in the analysis, the following three-factor solution is proposed (see Table 3): i) Factor 1, Memory and Learning: This factor included items related to episodic memory (1, 5 to 8, 24 and 28), learning (12) and language (13); ii) Factor 2, Attention: Items which loaded on this factor were more often related to concentration during conversations $(10,16,21)$, reading $(9,17)$ or watching movies (3); iii) Factor 3 , Procedure and Monitoring: The items of this factor were based on task monitoring of daily living $(14,15,18$, 22) and space (25).

Correlations among the three components were low: the correlation between components 1 and 2 was 0.21 and with component 3 was 0.21 ; correlation between components 2 and 3 was 0.12 .

\section{0-item EMQ and memory test performance}

We tested this revised EMQ version in our sample. To investigate the relationship between self-reported memory complaints and objective memory performance, we compared the EMQ scores obtained by the LP participants $(n=10)$, excluded from the original sample of 112 participants, with those obtained by NM participants. We selected a group of 20 (two controls for each case) NMs (mean age $=71.9 \pm 4.3$ yrs, mean education $=10.4 \pm 3.6$ ) from the dataset of NMs to be compared with the LP group. These two groups did not differ significantly as regards age $(\mathrm{t}(28)=1.45, p=0.15)$ or education $(\mathrm{t}(28)=-0.64, p=0.52)$.

Scores on the 20-item EMQ were lower in the NM $(M=44.6 \pm 16.7)$ than in the LP group $(M=75.1 \pm 24.4)$ $[t(28)=3.71, p<0.001]$. The first factor, Memory and Learning [LP group: $M=34.4 \pm 10.6$; NM group: $\mathrm{M}=24.2 \pm 10.4 ; \mathrm{t}(28)=2.47, p=0.02]$ and the third one, Procedure and Monitoring [LP group: $\mathrm{M}=26.2 \pm 11.5$; NM group: $\mathrm{M}=8.2 \pm 6.1 ; \mathrm{t}(28)=5.37, p<0.001]$ distinguished the two groups. Instead, the scores obtained on the sec- 
Table 3 - Final version of questionnaire (20 items) according to factor structure, with component loadings for each item.

\begin{tabular}{|c|c|c|c|c|}
\hline Item No. & Factor structure & Loadings & Means & SD \\
\hline & Factor 1 - Memory and Learning & & & \\
\hline 7 & I forget to take things with me & 0.92 & 2.64 & 1.47 \\
\hline 8 & I forget I was told something and had to be reminded & 0.79 & 3.11 & 1.93 \\
\hline 6 & I forget when something happened & 0.75 & 2.18 & 1.57 \\
\hline 5 & I have to go back to check whether I have done something & 0.55 & 3.48 & 2.16 \\
\hline 28 & I repeat to someone what I have just told them & 0.54 & 1.92 & 1.30 \\
\hline 12 & I have difficulty learning a new skill & 0.52 & 2.56 & 1.90 \\
\hline 13 & I find that a word is 'on the tip of my tongue' & 0.52 & 4.60 & 2.35 \\
\hline 24 & I forget where things are normally kept & 0.51 & 1.96 & 1.38 \\
\hline \multirow[t]{2}{*}{1} & I forget where I put things & 0.47 & 3.77 & 2.10 \\
\hline & Factor 2 - Attention & & & \\
\hline 16 & I forget what I have just said & 0.75 & 2.45 & 1.63 \\
\hline 10 & I let myself ramble on about unimportant or irrelevant things & 0.74 & 2.07 & 1.54 \\
\hline 21 & I tell someone a story or a joke I have told them already & 0.69 & 1.98 & 1.57 \\
\hline 17 & I am unable to follow the thread of a story & 0.62 & 2.40 & 1.83 \\
\hline 3 & I find television movies difficult to follow & 0.61 & 1.56 & 1.16 \\
\hline \multirow[t]{2}{*}{9} & I start to read something without realizing I have read it before & 0.42 & 2.02 & 1.69 \\
\hline & Factor 3 - Procedure and Monitoring & & & \\
\hline 18 & I forget to tell somebody something important & 0.84 & 2.08 & 1.23 \\
\hline 14 & I forget to do things I said I would do or planned to do & 0.73 & 2.37 & 1.74 \\
\hline 22 & I forget details of things I do regularly & 0.67 & 1.77 & 1.55 \\
\hline 25 & I get lost in places where I have often been before & 0.65 & 1.87 & 1.15 \\
\hline 15 & I forget important details of what I did the day before & 0.62 & 1.70 & 1.34 \\
\hline
\end{tabular}

ond factor (Attention) were not statistically different between the two groups [LP group: $\mathrm{M}=14.5 \pm 7.2 ; \mathrm{NM}$ group: $\mathrm{M}=11.6 \pm 6.5 ; \mathrm{t}(28)=1.30, \mathrm{p}=0.21]$. This means that attention is not one of the main factors that contributes toward differentiating the two groups on the total EMQ score, as factor 1 (Memory and Learning) and factor 3 (Procedure and Monitoring) do.

We also tested convergent validity by examining Pearson correlations between scores obtained on the revised EMQ and the cognitive performance (general cognitive status, Story Recall and executive functions), separately in NM and LP participants.

With respect to NM participants, a weak negative correlation between the EMQ total score and the MMSE score $(r=-0.37, p=0.02)$ was found. No other variable was correlated to the questionnaire score $(p>0.05)$.

Conversely, objective (Story Recall) and subjective (EMQ-revised) memory measures were highly correlated $(r=-0.69, p=0.03)$ in the LP group. Interestingly, the EMQ score did not correlate with any other cognitive measure (MMSE and TMT) in LP. Lastly, no changes were found after one year in the re-tested subgroup of NM participants for Story Recall [first assessment $=14.4 \pm 4.5$, second assessment $=14.3 \pm 3.8 ; \mathrm{t}(34)=0.15, p=0.89]$, MMSE [first assessment $=28.8 \pm 1.3$, second assessment $=28.8 \pm 1.2 ; \mathrm{t}(34)=0.11, p=0.91]$, TMT A [first as- sessment $=46.1 \pm 17.2$, second assessment $=44.1 \pm 20.3$; $\mathrm{t}(34)=0.75, p=0.46]$, TMT B [first assessment $=121.1 \pm 83.6$, second assessment $=125.4 \pm 60.1 ; \mathrm{t}(34)=-0.53, p=0.60]$ and EMQ score [first assessment $=47.8 \pm 16.1$, second assessment $=49.9 \pm 15.1 ; \mathrm{t}(34)=-1.70, p=0.10]$. This result confirms the reliability of the revised EMQ over time in NM individuals.

\section{DISCUSSION}

In this study of subjective and objective measures of memory in the elderly population, to evaluate their usefulness as assessed by the EMQ and determining the best factor structure for this purpose, we found that $8.9 \%$ of elderly adults had an objective memory deficit, matching literature data reporting a prevalence between about $6 \%(29,30)$ and $15 \%(31)$. We had recruited our participants by means of a newspaper advertisement for attending a course on aging-related changes of memory, and this method may have induced a bias in sample selection, but as we found the same prevalence of memory deficits as reported in previous studies, we can assume that our sample was representative of the elderly population.

In participants without memory deficits, we investigated the psychometric and factor structure of the EMQ. In our comparison of elderly participants with or without memory impairment, we found that a three-factor solution of 
20 items was more sensitive in differentiating the SMCs in the two groups. One previous study of EMQ and factor structure (15) reported a five-factor solution, whereas others $(13,15,16)$ have suggested three- or four-factor solutions. In our study, the final and more easily interpretable solution was a three-factor structure. This solution explained the $48 \%$ of total variance, the same percentage reported in other works applying a larger number of factors.

For example, Cornish (15) reported a five-factor solution, which explained $48.5 \%$ of total variance. Although this author eliminated some items with low means in a further analysis, he failed to find a different factor structure. His final solution considered the following factors: retrieval, task monitoring, conversational monitoring, spatial memory, and memory for activities. A similar structure was found also by Richardson and Chan (14), who used the EMQ to study SMCs in multiple sclerosis patients. They proposed a solution of five factors: receptive communication, route finding, absent-mindedness, face recognition, and expressive communication.

The differences between our factor structure and the ones previously reported may be due to differences in the sample cohort used. We considered elderly adults with a mean age of 70 years, whereas in Cornish's (15) study, participants had an age ranging from 19 to 45 and Richardson and Chan (14) studied a clinical population with a mean age of 48.6 years. Some differences with respect to previous studies may be attributed to age and agerelated changes in memory functioning (1). Our three-factor solution considered: a first factor including items related to episodic memory, learning and language; a second one more related to 'Attention' during conversation and reading; and a third considering items related to task monitoring of daily living. Cornish (15) reported similar factors in his solution: 'retrieval' for memory functioning, 'task monitoring' and 'memory for activities' similar to our 'procedure and monitoring'. In their revised version of the EMQ, Royle and Lincoln (16) also found a similar structure with two main factors, one related to memory retrieval and one to attentional tracking.

One crucial aim of the present study was to investigate the relationship between subjective and objective measures of memory in the elderly population, evaluating the usefulness of SMC assessment in them. With the revised shorter version of the EMQ, in this study we found that Low Performers (LP) i.e., those with objective memory deficits, obtained higher scores than elderly adults categorized as having Normal Memory (NM). These data suggest that the EMQ can provide reliable indications on memory ability in the elderly.

In addition, the correlation between the revised EMQ score and memory performance was obtained only in the LP group, in which the only significant correlation was that between the EMQ and Story Recall.
These results match those of the literature, suggesting that SMCs are correlated with memory impairment (for a recent review, see [9]), although some such studies give controversial results $(32,33)$. There is also increasing evidence that SMCs may be related to the risk of developing dementia (3).

It is noteworthy that we also analysed the reliability of EMQ scores over time in a subgroup of healthy participants. Retesting a subgroup of healthy subjects gave the same scores on the EMQ one year later, indicating that the present version is also reliable over time.

Altogether these preliminary data are really interesting for their scientific and clinical importance, they do need substantiation from a larger sample.

In conclusion, these results emphasize the importance and usefulness of this short revised version of the EMQ to predict objective memory impairment, since it may serve as an easy-to-use instrument to evaluate SMCs objectively in elderly adults, both in a clinical setting and in scientific investigations.

\section{APPENDIX 1}

20-item revised version of Everyday Memory Questionnaire (Italian version).

Deve rispondere al questionario utilizzando la scala dei punteggi da 1 a 9 come di seguito indicato.

Scala dei Punteggi

(vedere versione Inglese per la scala dei punteggi)

\begin{tabular}{|c|c|}
\hline $\begin{array}{l}\text { 1. Dimentico dove ho messo qualcosa. Perdo le cose per } \\
\text { casa }\end{array}$ & \\
\hline 2. Provo difficoltà a seguire un film alla TV & \\
\hline $\begin{array}{l}\text { 3. Devo tornare indietro per controllare se ho fatto } \\
\text { qualcosa che dovevo fare }\end{array}$ & \\
\hline $\begin{array}{l}\text { 4. Dimentico quando è successo qualcosa (per esempio, } \\
\text { non ricordo se una cosa è successa ieri o la settimana } \\
\text { scorsa) }\end{array}$ & \\
\hline 5. Dimentico di portare le cose con me & \\
\hline $\begin{array}{l}\text { 6. Dimentico che mi è stato detto qualcosa ieri o qualche } \\
\text { giorno fa, e devo farmelo ripetere }\end{array}$ & \\
\hline $\begin{array}{l}\text { 7. Comincio a leggere qualcosa (un libro, un articolo, o } \\
\text { una rivista) senza rendermi conto di averlo già letto }\end{array}$ & \\
\hline $\begin{array}{l}\text { 8. Mi accade di divagare, parlando di cose irrilevanti o } \\
\text { prive di importanza }\end{array}$ & \\
\hline $\begin{array}{l}\text { 9. Ho difficoltà ad imparare un'abilità nuova. Per } \\
\text { esempio, stento ad imparare un nuovo gioco o ad } \\
\text { usare un nuovo strumento dopo averci provato una } \\
\text { o due volte }\end{array}$ & \\
\hline $\begin{array}{l}\text { 10. Ho una parola "sulla punta della lingua". So che cos'è } \\
\text { ma non riesco a trovarla }\end{array}$ & \\
\hline $\begin{array}{l}\text { 11. Dimentico completamente di fare cose che mi è sta- } \\
\text { to detto di fare }\end{array}$ & \\
\hline $\begin{array}{l}\text { 12. Dimentico particolari importanti di ciò che ho fatto o } \\
\text { che mi è successo il giorno prima }\end{array}$ & \\
\hline
\end{tabular}




\section{APPENDIX 1 (continued)}

13. Quando parlo con qualcuno, mi capita di dimenticare ciò che ho appena detto. A volte dico "di che cosa stavamo parlando?"

14. Leggendo un giornale o una rivista, mi capita di non riuscire a seguire il filo di una storia, non ricordo più l'argomento

15. Dimentico di dire a qualcuno qualcosa di importante: per esempio, dimentico di trasmettere un messaggio o di ricordare qualche cosa a qualcuno

16. Racconto a qualcuno una storia o una barzelletta che gli avevo già raccontato

17. Dimentico particolari importanti di cose che faccio regolarmente. Per esempio non ricordo più i particolari di ciò che devo fare o quando devo farlo

18. Dimentico dove si trovano normalmente delle cose, o le cerco nel posto sbagliato

19. Mi perdo e giro nella direzione sbagliata nel corso di un viaggio, di una passeggiata, $\mathrm{o}$ in un edificio in cui sono stato spesso in precedenza

20. Ripeto a qualcuno una cosa che ho appena detto, oppure faccio due volte la stessa domanda

Punteggio Totale

\section{APPENDIX 2}

20-item revised version of Everyday Memory Questionnaire (English version)

Please rate the frequency with which you experience each event on a 9-point scale from 1 to 9, in agreement with the following table.

\section{Response Scale}

\begin{tabular}{|l|c|}
\hline Not at all in the last six months & 1 \\
\hline Once in the last six months & 2 \\
\hline $\begin{array}{l}\text { More than once in the last six months, but fewer } \\
\text { than once a month }\end{array}$ & 3 \\
\hline Once a month & 4 \\
\hline More than once a month, but fewer than once a week & 5 \\
\hline Once a week & 6 \\
\hline More than once a week, but fewer than once a day & 7 \\
\hline Once a day & 8 \\
\hline More than once a day & 9 \\
\hline
\end{tabular}

\begin{tabular}{|l|l|}
\hline 1. I forget where I put things & \\
\hline 2. I find television movies difficult to follow & \\
\hline $\begin{array}{l}\text { 3. I have to go back to check whether I had done } \\
\text { something }\end{array}$ & \\
\hline 4. I forget when something happened & \\
\hline 5. I forget to take things with me & \\
\hline 6. I forget I was told something and have to be reminded & \\
\hline $\begin{array}{l}\text { 7. I start to read something without realizing I have read } \\
\text { it before }\end{array}$ & \\
\hline
\end{tabular}

\begin{tabular}{|l|l|}
\hline $\begin{array}{l}\text { 8. I let myself ramble on about unimportant or irrelevant } \\
\text { things }\end{array}$ & \\
\hline 9. I have difficulty learning a new skill & \\
\hline 10. I find that a word is 'on the tip of my tongue' & \\
\hline 11. I forget to do things I said I would do or planned to do & \\
\hline 12. I forget important details of what I did the day before & \\
\hline 13. I forget what I have just said & \\
\hline 14. I am unable to follow the thread of a story & \\
\hline 15. I forget to tell somebody something important & \\
\hline 16. I tell someone a story or a joke I have told them & \\
already & \\
\hline 17. I forget details of things I do regularly & \\
\hline 18. I forget where things are normally kept & \\
\hline 19. I get lost where I have often been before & \\
\hline 20. I repeat to someone what I have just told them & \\
\hline Total score & \\
\hline
\end{tabular}

\section{REFERENCES}

1. Balota DA, Dolan PO, Duchek JM. Memory changes in healthy order adults. In Tulving E, Craik FIM, Eds. Oxford Handbook of Memory. Oxford: Oxford University Press, 2000: 395-403.

2. Spencer WD, Raz N. Differential effects of aging on memory for content and context: a meta-analysis. Psychol Aging 1995; 10 : 527-39.

3. Geerlings MI, Jonker C, Bouter LM, Ader HJ, Schmand B. Association between memory complaints and incident Alzheimer's disease in elderly people with normal baseline cognition. Am J Psychiatry 1999; 156: 531-7.

4. Jorm AF, Christensen H, Henderson AS et al. Complaints of cognitive decline in the elderly: a comparison of reports by subjects and informants in a community survey. Psychol Med 1994; 24 : 365-74.

5. Glodzik-Sobanska L, Reisberg B, De Santi S et al. Subjective memory complaints: presence, severity and future outcome in normal older subjects. Dement Geriatr Cogn Disord 2007; 24: 177-84.

6. Jonker C, Geerlings MI, Schmand B. Are memory complaints predictive for dementia? A review of clinical and population-based studies. Int J Geriatr Psychiatry 2000; 15: 983-91.

7. Schofield PW, Marder K, Dooneief G et al. Association of subjective memory complaints with subsequent cognitive decline in community-dwelling elderly individuals with baseline cognitive impairment. Am J Psychiatry 1997; 154: 609-15.

8. Jungwirth S, Fischer P, Weissgram S et al. Subjective memory complaints and objective memory impairment in the ViennaTransdanube aging community. J Am Geriatr Soc 2004; 52 : 263-8.

9. Reid LM, Maclullich AM. Subjective memory complaints and cognitive impairment in older people. Dement Geriatr Cogn Disord 2006; 22: 471-85. 
10. Zelinski EM, Gilewski MJ. Assessment of memory complaints by rating scales and questionnaires. Psychopharmacol Bull 1988; 24: 523-9.

11. Sunderland A, Harris JE, Baddeley AD. Do laboratory tests predict everyday memory? A neuropsychological study. J Verb Learn Verb Behav 1983; 22: 341-57.

12. Sunderland A. Assessing everyday memory after severe head injury. In Harris JE, Morris PE, Eds. Everyday Memory, Action, and Absent-Mindedness. London: Academic Press, 1984: 193-212.

13. Sunderland A, Watts K, Baddeley AD, Harris JE. Subjective memory assessment and test performance in elderly adults. J Gerontol 1986; 41: 376-84.

14. Richardson JT, Chan RC. The constituent structure of subjective memory questionnaires: evidence from multiple sclerosis. Memory 1995; 3: 187-200.

15. Cornish IM. Factor structure of the everyday memory questionnaire. Br J Psychol 2000; 91: 427-38.

16. Royle J, Lincoln NB. The Everyday Memory Questionnaire-revised: development of a 13-item scale. Disabil Rehabil 2008; 30: 114-21.

17. Petersen RC, Knopman DS. MCI is a clinically useful concept. Int Psychogeriatr 2006; 18: 394-402 (discussion 409-414).

18. Petersen RC. Mild cognitive impairment as a diagnostic entity. J Intern Med 2004; 256: 183-94.

19. Petersen RC, Smith GE, Waring SC et al. Mild cognitive impairment: clinical characterization and outcome. Arch Neurol 1999; 56: 303-8.

20. Roberts JL, Clare L, Woods RT. Subjective memory complaints and awareness of memory functioning in mild cognitive impairment: a systematic review. Dement Geriatr Cogn Disord 2009; 28: 95-109.

21. Ravaglia G, Forti P, Maioli F et al. Screening for mild cognitive impairment in elderly ambulatory patients with cognitive complaints. Aging Clin Exp Res 2005; 17: 374-9.

22. Basso C, Limongi F, Siviero $P$ et al. Cognitive impairment: classification and open issues. Aging Clin Exp Res 2007; 19: 344-8.
23. Folstein MF, Folstein SE, McHugh PR. "Mini-mental state". A practical method for grading the cognitive state of patients for the clinician. J Psychiatr Res 1975; 12: 189-98.

24. Novelli G, Papagno CC, Capitani E, Laiacona N, Vallar G, Cappa SF. Tre test clinici di memoria verbale a lungo termine. Archivio di Psicologia Neurologia e Psichiatria 1986: 278-96.

25. Giovagnoli AR, Del Pesce M, Mascheroni S, et al. Trail making test: normative values from 287 normal adult controls. Ital J Neurol Sci 1996; 17: 305- 9.

26. Lezak M, Howieson D, Loring DW. Neuropsychological Assessment (4th ed). Oxford: University Press, 2004.

27. Spinnler H, Tognoni P. Standardizzazione e taratura italiana di test neuropsicologici. Ital J Neurol Sci 1987; 6: 44-6.

28. Cattell R. The Scientific Use of Factor Analysis in the Behavioural and Life Sciences. New York: Plenum, 1978.

29. Kumar R, Dear KB, Christensen $\mathrm{H}$ et al. Prevalence of mild cognitive impairment in 60- to 64-year-old community-dwelling individuals: The Personality and Total Health through Life 60+ Study. Dement Geriatr Cogn Disord 2005; 19: 67-74.

30. Kivipelto M, Helkala EL, Hanninen T et al. Midlife vascular risk factors and late-life mild cognitive impairment: a populationbased study. Neurology 2001; 56: 1683-9.

31. Frisoni GB, Fratiglioni L, Fastbom J et al. Mild cognitive impairment in the population and physical health: data on 1,435 individuals aged 75 to 95. J Gerontol A Biol Sci Med Sci 2000; 55 : M322-8

32. Clarnette RM, Almeida OP, Forstl H, Paton A, Martins RN. Clinical characteristics of individuals with subjective memory loss in Western Australia: results from a cross-sectional survey. Int J Geriatr Psychiatry 2001; 16: 168-74.

33. Riedel-Heller SG, Matschinger H, Schork A, Angermeyer MC. Do memory complaints indicate the presence of cognitive impairment? Results of a field study. Eur Arch Psychiatry Clin Neurosci 1999; 249: 197-204. 